\title{
Effects of Unsaturated Fatty Acid Esters of Testosterone on Neuronal, Behavioral and Hormonal Parameters in Male Rats Subjected to the Formalin Test
}

\author{
Anna Petroni ${ }^{1}$, Paolo Fiorenzani' ${ }^{2}$, Valentina Tomei ${ }^{2}$, Antonio Garofalo 3 , Francesca Aiello ${ }^{3}$, \\ Daniele Della Seta², Antonio Giordano², Stella Vodo², Ilaria Ceccarelli², Anna Maria Aloisi2 ${ }^{2 *}$ \\ ${ }^{1}$ Department of Pharmacological and Biomolecular Sciences, University of Milan, Milan, Italy \\ ${ }^{2}$ Department of Medicine, Surgery and Neuroscience, University of Siena, Siena, Italy \\ ${ }^{3}$ Department of Pharmacy and Health Nutrition Sciences, University of Calabria, Rende, Italy \\ Email: *annamaria.aloisi@unisi.it
}

Received 23 February 2014; revised 23 March 2014; accepted 20 April 2014

Copyright (C) 2014 by authors and Scientific Research Publishing Inc.

This work is licensed under the Creative Commons Attribution International License (CC BY). http://creativecommons.org/licenses/by/4.0/

(c) (i) Open Access

\section{Abstract}

Chronic diseases are often accompanied by inflammatory and degenerative processes. Estrogens have repeatedly been found to be involved in these processes. Testosterone $(T)$ is the main precursor of estrogen in the brain and $T$ replacement in chronic diseases has become important in recent years, prompting research on new $\mathrm{T}$-conjugated molecules. We recently synthesized three new molecules including unsaturated fatty acid esters: T-linoleate (TL), T-oleate (TO) and T-eicosapentanoate (TEPA). These substances were s.c. administered for 7 days to intact male rats subjected to the formalin test (FT). Three other groups were included as comparisons: NAIVE, receiving no substance, OIL, treated with almond oil (vehicle), and TN, treated with T-undecanoate, a saturated fatty acid. Spontaneous behaviors and pain-induced responses were determined during the FT, hormones (T and dihydrotestosterone, DHT) were determined in blood, while estrogen receptors (ER $\alpha$ and $\beta$ ) were detected at the genomic and proteomic levels in the hippocampus, hypothalamus and spinal cord. In the hippocampus, ER $\alpha$ and ER $\beta$ mRNA levels were increased respectively by TN and TL treatments with respect to OIL, whereas the hypothalamus TO and TL caused a decrease of ER $\alpha$ mRNA levels. At the proteomic level, TO, TL and TEPA decreased the levels of ER $\alpha$ in the hypothalamus, whereas TEPA decreased ER $\beta$ in the spinal cord, hippocampus and hypothalamus. There was no effect of treatment on the spontaneous behaviors, while the TO and TL groups showed lower pain-induced behaviors (paw jerk frequency and licking duration) than the OIL group. TN increased paw jerk frequency and decreased licking duration with respect to

"Corresponding author.

How to cite this paper: Petroni, A., et al. (2014) Effects of Unsaturated Fatty Acid Esters of Testosterone on Neuronal, Behavioral and Hormonal Parameters in Male Rats Subjected to the Formalin Test. Open Journal of Endocrine and Metabolic Diseases, 4, 167-179. http://dx.doi.org/10.4236/ojemd.2014.46017 
OIL. The treatments had no effect on T and DHT plasma levels. These results clearly indicate the possibility of pain and ER modulation by T-esters.

\title{
Keywords
}

\author{
Testosterone, CNS, Fatty Acids, Pain, Estrogen Receptors
}

\section{Introduction}

Testosterone (T) is increasingly recognized as a modulator of CNS processes and not only those related to reproduction. Adequate $\mathrm{T}$ serum levels are required in males and females for cellular growth, healing, maintenance of muscle mass and bone, as well as CNS maintenance of opioid receptors, the blood-brain barrier and dopamine-norepinephrine activity [1]-[3]. Other important functions are involved in the occurrence and modulation of pain. Indeed, numerous studies suggest that testosterone and its metabolites can influence pain processing [4]-[8] via both rapid and slow signals [9] [10]. Indirect proof of these actions is the fact that women suffer chronic painful syndromes more than men do [11] [12] and there are negative correlations between $\mathrm{T}$ levels and pain, i.e. lower pain in subjects with higher T levels [13]. We have reported beneficial effects of testosterone replacement therapy in chronic pain patients rendered hypogonadic by chronic assumption of opioids [14]. In experimental studies, testosterone was demonstrated to be analgesic in a variety of nociceptive tests [15] [16]. Moreover, a recent study in humans demonstrated the ability of $\mathrm{T}$ to modulate descending inhibitory pain pathways in women [17].

Testosterone is an androgen present in both sexes. It is considered a pro-hormone since most of its actions depend on the enzymes present in the cell: $5 \alpha$-reductase reduces it to dihydrotestosterone (DHT) which acts like $\mathrm{T}$ on androgen receptors (AR); aromatase aromatizes it to estradiol (E2) which acts on estrogen receptors (ER $\alpha$ and ER $\beta$ ) [6]. Both AR and ER are widely distributed throughout the CNS, e.g. spinal cord, hippocampus and hypothalamus targets for gonadal hormone actions involved in different aspects of pain modulation. In particular, the hippocampus is mostly involved in arousal, learning and memory and can play a significant role in pain modulation, as shown by different experimental approaches in both animal and human subjects [18]-[22]. ER are known to be involved in these functions; indeed $\operatorname{ER} \alpha$ and $\operatorname{ER} \beta$ have many enhancing effects on neuronal plasticity, behaviors related to cognition and mood [23] [24], and degenerative processes [25].

Due to aging or iatrogenic causes, testosterone levels may substantially decline and hypogonadic patients may experience symptoms of androgen deficiency including sexual dysfunction, dysphoric mood (anxiety, irritability and depression), lack of well-being, physical fatigue, changes in cognition, memory loss, insomnia, rheumatoid complaints, and pain [26]. Tajar et al. (2011) [27] reported that elevated levels of gonadotropins, but not sex steroids, are significantly associated with musculoskeletal pain in men. Recent studies also demonstrated a positive action of $\mathrm{T}$ on weight control in obese patients [28]. Testosterone compounds are usually based on $\mathrm{T}$ esterified with different molecules. One of the most commonly used long-term preparations is T esterified with the saturated fatty acid (FA) undecanoate to obtain testosterone undecanoate (TN). However, saturated FAs esterified with $\mathrm{T}$ could be hydrolyzed and follow metabolic pathways that might contribute to cardiovascular disease [29]. Therefore, we have explored the possibility of creating new substances in which $\mathrm{T}$ is esterified with unsaturated fatty acids. These esters could also have beneficial effects on chronic disorders [30], including the prevention of hypercholesterolemia, atherosclerosis and inflammatory disease [31].

Estrogen receptors are widely distributed in the brain. Their neuroprotective actions are summarized in a recent review [25] in which the focus is on astrocytes in addition to the known effects on neurons. In astrocytes, estrogens are actively synthesized from testosterone via aromatase. This process can be greatly increased by injury through enhancement of aromatase activity. We have shown strong modulation of aromatase by morphine in in vitro experiments on astrocytes [32].

The main goal of the present study was to investigate neural, behavioral and hormonal effects of supraphysiological testosterone levels induced by s.c. injection into gonadally intact males rats of newly synthesized [33] T esters (testosterone-oleate: TO, testosterone-linoleate: TL, testosterone-eicosapentaenoic acid: TEPA) with respect to the commercially available testosterone undecanoate (Testosterone Nebid ${ }^{\circledR}$, TN), used as the reference 
compound. We investigated the effects of the various $\mathrm{T}$ ester treatments on spontaneous and formalin-induced behaviors, testosterone and dihydrotestosterone (DHT) plasma levels, and $\operatorname{ER} \alpha$ and $\operatorname{ER} \beta$ levels in the hippocampus, hypothalamus and spinal cord.

\section{Materials and Methods}

\subsection{Subjects}

Thirty-six male Wistar Han rats (Harlan-Nossan, Milan, Italy), weighing 200 - 225 grams at their arrival, were housed two per cage in plastic-bottomed cages with sawdust bedding. In each cage the animals were separated by a transparent Plexiglas wall with holes to allow partial social interactions. Cages were kept at room temperature $21^{\circ} \mathrm{C} \pm 1{ }^{\circ} \mathrm{C}$, relative humidity $60 \% \pm 10 \%$ and on a $12 / 12 \mathrm{~h}$ light/dark cycle (light off at 7 a.m.). Animals received food and water ad libitum.

\subsection{Experimental Procedures}

Experiments were carried out during the rats' active period between 09:30 a.m. and 12:30 p.m. in a dedicated room under red light and white background noise. The experimental procedures were pre-approved by the ethics committee of the University of Siena and the National Institution for experiments in living animals. In all experiments, attention was paid to the regulations for handling laboratory animals of the European Communities Council Directive (86/609/EEC) and the ethical guidelines for investigation of experimental pain in conscious animals issued by the ad hoc Committee of the International Association for the Study of Pain [34]. Particular efforts were made to minimize animal suffering and to reduce the number of animals used.

One week after their arrival, the animals were randomly assigned to one of the experimental groups ( $n=6$ per group) according to the substance they would receive: T-undecanoate (TN, Nebid ${ }^{\circledR}$, Bayer), T-oleate (TO), Tlinoleate (TL), T-eicosapentaenoic acid (TEPA). All drugs were dissolved in sweet almond oil (OIL, vehicle, Laboratorio Farmaceutico Veneto FARVE, Italy) to obtain $1 \mathrm{mg} / \mathrm{ml}$ solutions to be administered to animals in a $1 \mathrm{mg} / \mathrm{Kg} /$ die dosage according to the most recent determination of the animal's body weight. The following groups were obtained: NAIVE (without any substance administration) and OIL, TN, TO, TL and TEPA (all s.c. injected with the relevant substance).

All animals were treated from day 1 to day 7 (7 days). Treatment consisted in a subcutaneous (s.c.) injection of one of the substances on the back of the animal. Immediately after the injection, the rat was returned to its home cage. To evaluate possible changes in spontaneous and anxious behaviors after 5 days of treatment, all rats were subjected to the open field test (OF) for $30 \mathrm{~min}$ and to the elevated plus maze test for 5 min on day 5 . On day 6, all rats were subjected to the formalin test to evaluate the effects of the treatment on the responses to a nociceptive stimulus: after receiving a s.c. injection of dilute formalin $(50 \mu 1,5 \%)$ in the dorsal hind paw, they were placed in the open field apparatus and their behavior was recorded for $60 \mathrm{~min}$. The day following the last s.c. treatment (day 8), the animals were anesthetized and perfused to allow tissue and blood collection.

\subsection{Open Field Test (Day 5)}

This test was carried out to study the treatment-induced effects on general behavior. Subjects were tested in an open field apparatus after 5 days of treatment. Both subjects of each home-cage were simultaneously transported to the experimental room (supplied with red light and white noise) and placed in identical open field apparatuses consisting of square Plexiglas cages $(50 \times 50 \mathrm{~cm}, 40 \mathrm{~cm}$ high). During the test (30 min), spontaneous behaviors were recorded and analyzed in six 5-min periods. The spontaneous behaviors considered were: rearing frequency (number of times the animals stood on their fore limbs), self-grooming duration (time spent washing or scratching the face or body), locomotion duration (time spent sniffing and exploring the environment), sit alert duration (time spent motionless in an alert position), crouch (time spent motionless in a sleeping-like position); locomotor activity was also evaluated by counting the inner crossing (number of times the animal crossed the internal squares) and outer crossing (number of times the animal crossed the external squares).

\subsection{Elevated plus Maze (Day 5)}

The elevated plus maze apparatus consists of two open arms $(50 \times 10 \mathrm{~cm})$ and two enclosed arms $(50 \times 10 \times 40$ 
$\mathrm{cm}$ high) opposite each other at $50 \mathrm{~cm}$ above the floor. At the beginning of the test, the rat was placed in the centre of the elevated plus maze and was then allowed to freely explore for $5 \mathrm{~min}$. The testing room was quiet and lit with dim red light. The test was performed immediately after the OF test. The time the animal spent exploring the open arms was considered for the statistical analysis.

\subsection{Formalin Test (Day 6)}

For evaluation of the treatment-induced effects on persistent inflammatory pain, both subjects of a cage were simultaneously transported to the experimental room on day 6 . They were gently restrained and s.c. injected with freshly prepared formalin solution ( $5 \%$ in $0.9 \% \mathrm{NaCl}$ in a micro-syringe) on the dorsal surface of the right hind paw. After the injection, the rats were placed in the open field apparatus for $60 \mathrm{~min}$. For assessment of the pain intensity and the behavioral effects of treatment, spontaneous and formalin-evoked behaviors were recorded for 60 min and analyzed in twelve 5-min periods. The analyzed behaviors were:

1) Formalin-induced responses: licking duration (time spent licking the injected foot); flexing duration (time spent with the leg held off the floor, flexed close to the body); paw jerk frequency (number of phasic flexions of the leg).

2) Spontaneous behaviors: the same behaviors analyzed in the open field test were considered, i.e. rearing frequency, self-grooming, locomotion, sit alert and crouch duration; locomotor activity (counting of inner crossing and outer crossing).

\subsection{Tissue Collection (Day 8)}

Twenty-four hours after the last treatment carried out on Day 7, the rats were anesthetized with sodium pentobarbital (>100 mg/kg i.p.) and the abdomen was opened to collect blood. The animals were then intracardially perfused with phosphate buffered saline (PBS, about $300 \mathrm{ml}$ ) for exsanguination of the CNS. The spinal cord, hypothalamus and hippocampus were then collected. Tissues were divided into portions, immediately frozen in liquid nitrogen and stored at $-80^{\circ} \mathrm{C}$ for western blot analysis and RNA isolation.

\subsection{RNA Extraction and Quantitative Real-Time Polymerase Chain Reaction (qRT-PCR)}

Total RNA from the hypothalamus, hippocampus and spinal cord was extracted and purified with the miRNeasy mini kit (Qiagen, Valencia, CA) following the manufacturer's instructions. The RNA concentration was determined with a NanoDrop ND-100 spectrophotometer. qRT-PCR was performed to monitor the gene expression levels of $\mathrm{ER} \alpha$ and $\mathrm{ER} \beta$. Five hundred nanograms of RNA were reverse transcribed with the iScript cDNA Synthesis kit (Bio-Rad) for $5 \mathrm{~min}$ at $25^{\circ} \mathrm{C}, 30 \mathrm{~min}$ at $42^{\circ} \mathrm{C}$ and $5 \mathrm{~min}$ at $85^{\circ} \mathrm{C}$. One microliter of cDNA was amplified by RT-PCR using the Opticon II (Bio-Rad) and the SsoFast Eva-Green Master Mix (Bio-Rad) according to the manufacturer's instructions. Forty PCR cycles were performed using an annealing temperature of $56^{\circ} \mathrm{C}$ for $\mathrm{ER} \alpha$ and $58^{\circ} \mathrm{C}$ for ERß. Primers were specifically designed between two adjacent exons and synthesized by MWG. mRNA levels for each gene were normalized to those of Cyclofilin and the gene expression was analyzed using the $\Delta \Delta \mathrm{Ct}$ method.

The primer sequences were:

1) $\operatorname{ER} \alpha$

Forward: AATTCTGACAATCGACGCCAG;

Reverse: GTGCTTCAACATTCTCCСTCCTC.

2) $\mathrm{ER} \beta$

Forward: AAAGCCAAGAGAAACGGTGGGCAT;

Reverse: GCCAATCATGTGCACCAGTTCCTT.

3) Cyclofilin

Forward: ACACGCCATAATGGCACTGG;

Reverse: ATTTGCCATGGACAAGATGCC.

\subsection{Western Blot}

The hypothalamus, hippocampus and spinal cord tissue samples were homogenized (using a tissue homogenizer) in RIPA-B buffer (20 mmol/l sodium phosphate buffer, $150 \mathrm{mmol} / \mathrm{l} \mathrm{NaCl}, 5 \mathrm{mmol} / \mathrm{l}$ EDTA, 1\% Triton X-100, 
and $0.5 \%$ sodium deoxycholate) supplemented with one tablet of cOmplete, Mini EDTA-free protease inhibitor cocktail (Roche Diagnostic, Mannheim, Germany) and sodium orthovanadate (1 mmol/l, pH 7.4). The homogenates were clarified by centrifugation at $15,000 \mathrm{~g}$ for $15 \mathrm{~min}$ at $4^{\circ} \mathrm{C}$ and prepared for immunoblot analysis.

Total protein concentrations were determined via the Bio-Rad $\mathrm{D}_{\mathrm{c}}$ protein assay protocol (Bio-Rad, Hercules, CA) followed by spectrophotometric analysis using the TECAN Genios plate reader and Magellan version 4.0 software. Equal amounts of protein $(50 \mu \mathrm{g})$ were loaded in each well, separated on SDS-PAGE gel (10\% gradient gel; Bio-Rad, Hercules, CA) and transferred to nitrocellulose membranes (Millipore, Bedford, MA). The membranes were blocked with $3 \%$ milk and incubated overnight at $4^{\circ} \mathrm{C}$ with a primary antibody ER $\alpha$ rabbit polyclonal antibody (1:500; Santa Cruz Biotechnology, Santa Cruz, CA) and ER $\beta$ rabbit polyclonal antibody (1:500; Santa Cruz Biotechnology, Santa Cruz, CA). Primary antibody incubation was followed by incubation for $1 \mathrm{~h}$ at room temperature with horseradish peroxidase-conjugated secondary antibody (1:3000; Bio-Rad goat anti-rabbit). The blots were visualized in enhanced chemiluminescence solution (HRP chemiluminescence detection kit, Bio-Rad) for 5 min and exposed to X-ray film (Thermo scientific, Pierce Biotechnology, Rockford, IL, USA) for 5 - 20 min. Equal loading of the proteins was confirmed by staining the blots with a $10 \%(\mathrm{v} / \mathrm{v})$ Ponceau S solution (2\% Ponceau S in 30\% trichloroacetic acid/30\% sulfosalicylic acid, Sigma Chemical Co). The ratio of the densitometric values obtained in the estrogenic-specific chemiluminescence reaction and the major Ponceau S-stained membrane bands (loading control) was calculated. The western blot analysis was performed in triplicate. The band density was measured with a computer-assisted imaging analysis program (Quantity One Software, Bio-Rad, Milan, Italy) and normalized against the corresponding loading control.

\subsection{Hormone Determinations}

Blood samples were collected from the abdominal vein in EDTA-added syringes. Blood was centrifuged (3000 $\mathrm{g}$ for $10 \mathrm{~min}$ at $4^{\circ} \mathrm{C}$ ) to obtain plasma and the samples were then frozen at $-20^{\circ} \mathrm{C}$ until the assay. The ADVIA Centaur assay, a competitive immunoassay using direct chemiluminescent technology, was used to measure testosterone (T) and dihydrotestosterone (DHT) plasma levels. The intra-assay and inter-assay coefficients of variation were $5 \%$ and $8 \%$ respectively for all determinations.

\subsection{Statistical Analysis}

The pain response data were processed by analysis of variance (ANOVA) with the factors Treatment (five levels: OIL, TN, TO, TL, TEPA) and Time (twelve 5-min intervals), whereas spontaneous behaviors recorded during the formalin and open field tests were analyzed as total values of each behavior with the factor Treatment (five levels: OIL, TN, TO, TL, TEPA). The elevated plus maze, hormone, western blot and RT-PCR data were processed by one-way ANOVA with the factor Treatment (five levels: OIL, TN, TO, TL, TEPA), followed by the post-hoc Bonferroni test. GraphPad Prism Version 4.0 (GraphPad Software, Inc., San Diego, CA) was used and the significance level was set at $\left(^{*}\right) \mathrm{p}<0.05$.

\section{Results}

The weight and general physical condition of each rat were checked during the experimental phases. No abnormal weight changes or signs of physical impairment were observed.

\subsection{Effects of Treatments on Estrogen Receptor (ER $\alpha$ and ER $\beta$ ) mRNA Levels}

mRNA levels of ER $\alpha$ and ER $\beta$ were determined by quantitative RT-PCR in the hypothalamus and hippocampus samples. In Figure 1, the data are represented as fold change with respect to the NAIVE level (gene expression $=1)$.

For ER $\alpha$ gene expression in the hippocampus (Figure $1(\mathrm{~A})$ ), the significant effect of Treatment $\left(\mathrm{F}_{4,19}=2.244\right.$, $\mathrm{p}=0.0002)$ was due to differences among groups: TN showed higher levels than OIL $(\mathrm{p}<0.01)$, TO $(\mathrm{p}<0.05)$ and TL ( $<0.001)$; moreover, TEPA had a higher level than TL $(\mathrm{p}<0.05)$. In the hypothalamus (Figure $1(\mathrm{~B})$ ), the significant effect of Treatment $\left(\mathrm{F}_{4,29}=6.300, \mathrm{p}=0.0012\right)$ was due to the lower levels in TO and TL than in OIL ( $\mathrm{p}<0.01$ for both).

For ER $\beta$ gene expression in the hippocampus (Figure $1(C)$ ), TL had higher levels than OIL $(\mathrm{p}<0.05)$ (Treatment: $\left.F_{4,29}=3.421, p=0.0231\right)$. No significant effect of treatment was found for the hypothalamus $\left(\mathrm{F}_{4,29}=\right.$ 2.2431, $\mathrm{p}=0.0931$ ) (Figure 1(D)). 
A Hippocampus mRNA ER alpha

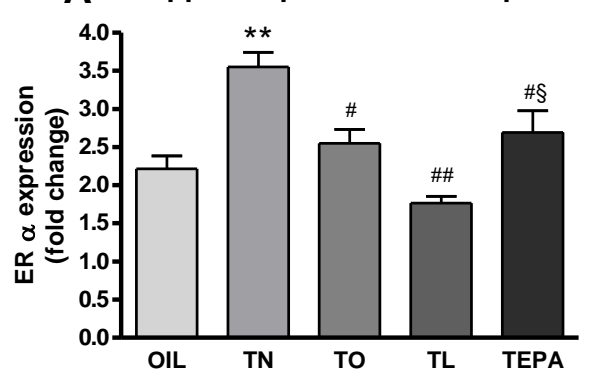

C Hippocampus mRNA ER beta

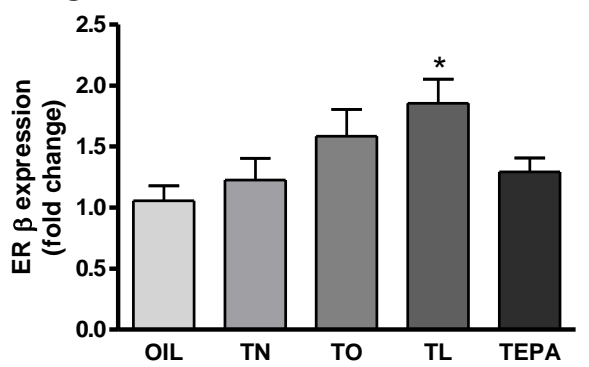

B Hypothalamus mRNA ER alpha

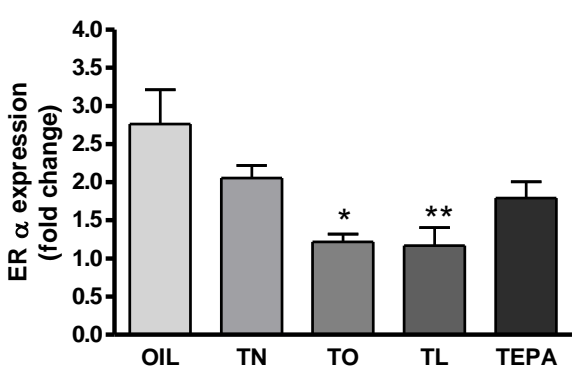

D Hypothalamus mRNA ER beta

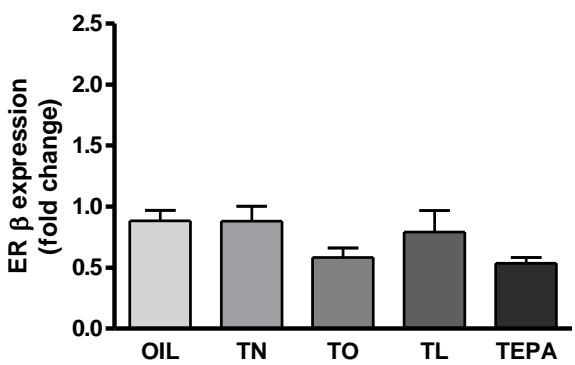

Figure 1. RT-PCR analysis. Quantification of $\operatorname{ER} \alpha((\mathrm{A})$ and (B)) and $\operatorname{ER} \beta((\mathrm{C})$ and (D)) mRNA levels in the hypothalamus ((B) and (D)) and hippocampus ((A) and (C)) of treated animals (OIL, TN, TP, TO, TL and TEPA). Data are shown as mean \pm SEM of fold changes with respect to the NAIVE group (not shown). ${ }^{*} \mathrm{p}<0.05$ and ${ }^{* *} \mathrm{p}<0.001$, vs OIL; ${ }^{*} \mathrm{p}<0.05$ and ${ }^{\# \#} \mathrm{p}<0.001$, vs TN; ${ }^{\S} \mathrm{p}<0.05$, vs TL.

\subsection{Effects of Treatments on CNS ER $\alpha$ and ER $\beta$ Levels}

We performed western blot analysis to demonstrate treatment effects on $\operatorname{ER} \alpha$ and $\operatorname{ER} \beta$ proteins in the hypothalamus, hippocampus and spinal cord. In the hypothalamus and hippocampus, ER $\alpha$ expression was detected as a full-length $\mathrm{ER} \alpha$ band at $66 \mathrm{kDa}$ and another immunoreactive band at $52 \mathrm{KDa}$, as already reported [35]. No detectable $\mathrm{ER} \alpha$ protein levels were found in the spinal cord.

One-way ANOVA showed no significant effect of Treatment on ER $\alpha$ levels in the hippocampus $\left(\mathrm{F}_{4,12}=1.441\right.$, $\mathrm{p}=0.3053$, Figure 2(A)) or in the hypothalamus (F4,13 $=3.316, \mathrm{p}=0.0625$, Figure 2(B)).

In the same CNS regions, $\mathrm{ER} \beta$ protein expression was detected as a single band at $55 \mathrm{kDa}$.

There was a significant effect of Treatment on ER $\beta$ levels in the spinal cord $\left(\mathrm{F}_{4,16}=3.466, \mathrm{p}=0.0421\right.$, Figure $3(\mathrm{~A})$ ) due to the lower levels in TEPA-treated animals than in OIL-treated ones $(\mathrm{p}<0.05)$. In the hippocampus (Figure 3(B)), there was a significant effect of Treatment $\left(\mathrm{F}_{4,14}=3.538, \mathrm{p}=0.0478\right)$, which tended to be lower in animals treated with TL and TEPA. The significant effect of Treatment $\left(\mathrm{F}_{4,9}=5.366, \mathrm{p}=0.047\right)$ in the hypothalamus (Figure 3(C)) was due to the lower levels in TO, TL and TEPA than in OIL ( $\mathrm{p}<0.05$ for all).

\subsection{Behavioral Data}

\subsubsection{Open Field ( $30 \mathrm{~min})$}

One-way ANOVA was applied to the total spontaneous behaviors recorded during the open field test with the factor Treatment (five levels: OIL, TN, TO, TL, TEPA, see Table 1). There was a significant effect of Treatment on grooming duration $\left(\mathrm{F}_{5,30}=3.232, \mathrm{p}=0.02\right)$, since TO showed a higher value than OIL ( $\left.<0.01\right)$, TN ( $\mathrm{p}$ $<0.01)$ and TL $(\mathrm{p}<0.01)$. Crouch duration was significantly different among groups $\left(\mathrm{F}_{5,30}=2.804, \mathrm{p}=0.034\right)$ : TO was higher than OIL and TEPA ( $<<0.01$ and $\mathrm{p}<0.04$, respectively) and TL was higher than OIL ( $<0.01$ ). Sit alert and locomotion duration and rearing frequency were not affected by the treatment.

Locomotor activity was also evaluated by counting of internal and external crossing. However, Treatment had a significant effect only on internal crossing $\left(\mathrm{F}_{5,30}=2.73, \mathrm{p}=0.038\right)$ : TL showed lower internal crossing than OIL and TN ( $<<0.004, p<0.05$, respectively) while TEPA was lower than OIL ( $<<0.03)$. 

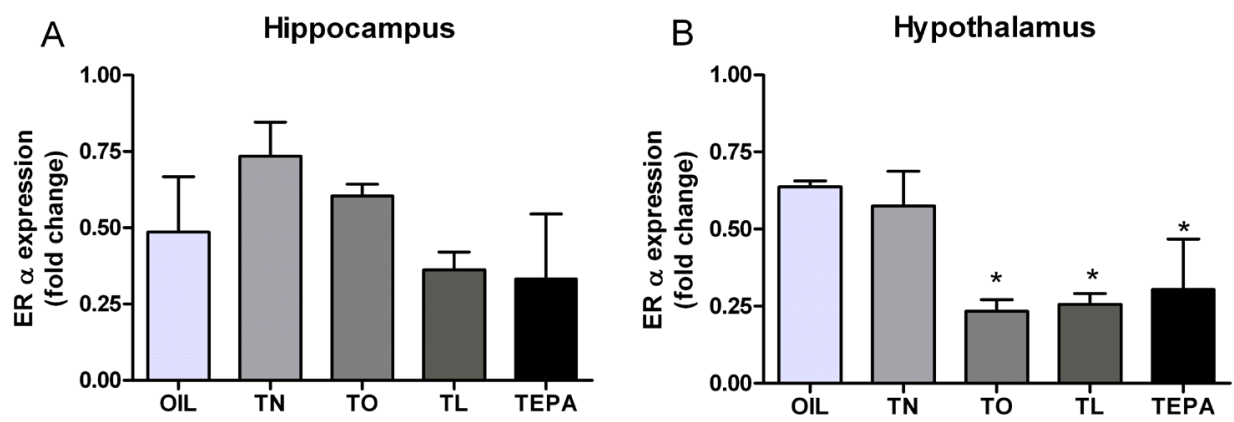

Figure 2. Western blot analysis and identification of ER $\alpha$ protein in rat CNS tissues. (Left) Data (mean \pm SEM) are expressed as fold change with respect to NAIVE. (Right) Ponceau staining shows equal protein loading. ${ }^{*} \mathrm{p}<0.05$ OIL.
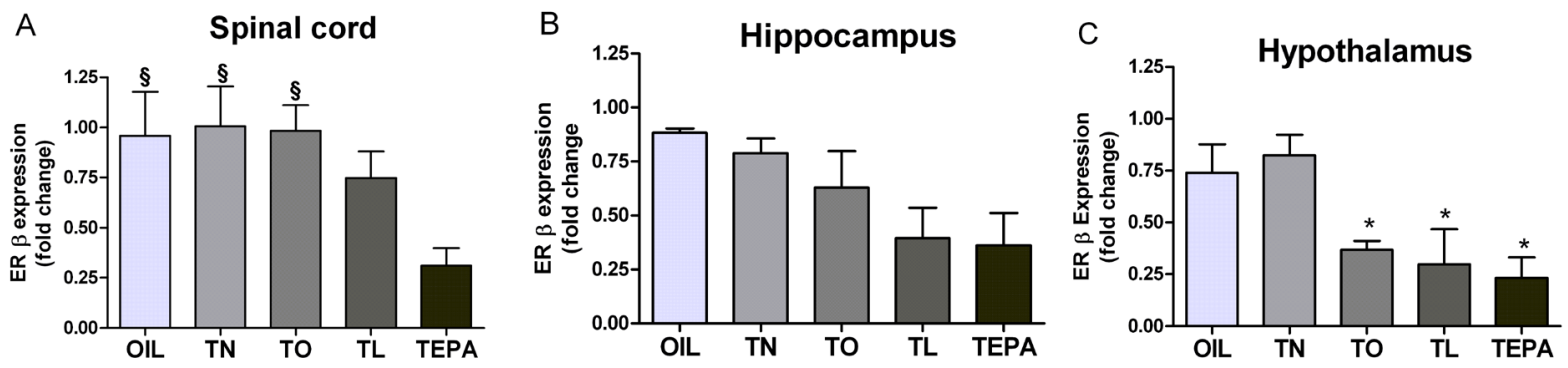

Figure 3. Western blot analysis and identification of ER $\beta$ protein in CNS tissues. (Left) Data (mean \pm SEM) are expressed as fold increase with respect to NAIVE. (Right) Representative western blot analysis of ER $\beta$ in the spinal cord (A), hippocampus (B) and hypothalamus (C) of treated animals (OIL, TN, TO, TL, TEPA). ${ }^{*} \mathrm{p}<0.05$ OIL, ${ }^{\S} \mathrm{p}<0.05$ vs TEPA.

Table 1. Table of total spontaneous behaviors determined during the open field test (30 min) in animals belonging to the five treated groups (OIL, TN, TO, TL, TEPA). Data represent the mean \pm SEM of the total time or frequency of each behavior. "vs TO, $\mathrm{p}<0.01$ for all; ${ }^{*}$ vs OIL, $\mathrm{p}<0.03$; ${ }^{\S}$ vs TL, $\mathrm{p}<0.01$.

\begin{tabular}{cccccc}
\hline Behaviors & OIL & TN & TO & TL & TEPA \\
\hline Internal Crossing (n) & $102.3 \pm 19.4^{\S}$ & $80.2 \pm 12.5^{\S}$ & $62.8 \pm 5.7$ & $41.8 \pm 54.5$ & $58.0 \pm 7.4^{\S}$ \\
External Crossing (n) & $349.7 \pm 35.6$ & $232.8 \pm 41.1$ & $356.7 \pm 36.1$ & $296.8 \pm 54.5$ & $340.5 \pm 20.3$ \\
Locomotion (sec) & $1294.5 \pm 113.1$ & $1223.0 \pm 101.1$ & $975.3 \pm 65.9$ & $1106.2 \pm 143.3$ & $1151.5 \pm 122.7$ \\
Sit Alert (sec) & $237.0 \pm 84.9$ & $156.2 \pm 70.5$ & $109.7 \pm 25.0$ & $167.7 \pm 64.2$ & $206.0 \pm 53.0$ \\
Grooming (sec) & $207.5 \pm 43.7^{*}$ & $207.2 \pm 39.3^{*}$ & $361.2 \pm 49.5$ & $198.8 \pm 27.5^{*}$ & $297.7 \pm 55.0$ \\
Rearing (sec) & $130.8 \pm 20.9$ & $91.8 \pm 16.7$ & $79.5 \pm 11.7$ & $86.5 \pm 15.8$ & $104.0 \pm 7.2$ \\
Crouch (sec) & $61.0 \pm 25.0^{*}$ & $213.7 \pm 74.6$ & $355.8 \pm 93.8$ & $328.3 \pm 89.1^{*}$ & $144.8 \pm 28.3^{*}$ \\
\hline
\end{tabular}

\subsubsection{Elevated plus Maze}

One-way ANOVA applied to the time spent by animals exploring the open arms did not reveal any significant difference among groups.

\subsubsection{Formalin Test}

1) Pain-induced responses

Formalin-induced responses were analyzed by repeated measure ANOVA applied to each pain response (licking, flexing and jerking of the injected paw) with the factors Treatment (five levels: OIL, TN, TO, TL, TEPA) and Time (twelve 5-min intervals).

2) Paw jerk 
There was a strong tendency towards a significant Treatment $\times$ Time interaction $\left(\mathrm{F}_{44,275}=1.3914, \mathrm{p}=0.060\right)$. Post-hoc analysis revealed some significances that need to be underlined in light of the neural response. In particular, TO had lower levels than OIL at 20 and $50 \min (\mathrm{p}<0.01$ and $\mathrm{p}<0.03$, respectively), while TN was higher than OIL from 35 to $45 \mathrm{~min}$ ( $\mathrm{p}<0.04$ and $\mathrm{p}<0.01$, respectively) (Figure 4(A)).

3) Licking

Licking duration was only affected by Treatment in the first phase $(0-5 \mathrm{~min})\left(\mathrm{F}_{4,25}=32.98, \mathrm{p}=0.038\right)$ due to higher levels in OIL than in TN $(\mathrm{p}<0.01)$, TO $(\mathrm{p}<0.04)$ and TL $(\mathrm{p}<0.004)$. No significant differences among groups were found in the second phase (Figure 4(B)).

4) Flexing

Repeated measure ANOVA did not reveal any significant differences among groups in flexing duration (Figure 4(C)).

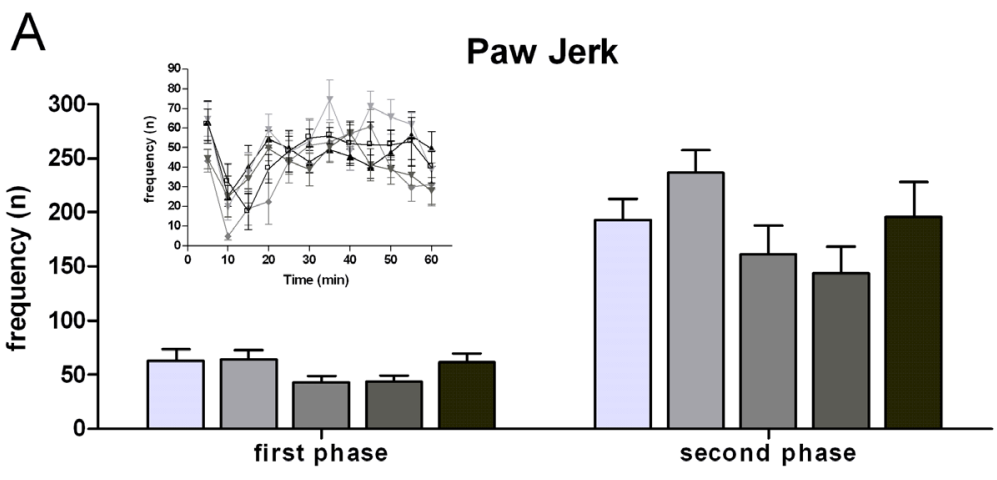

\section{B}

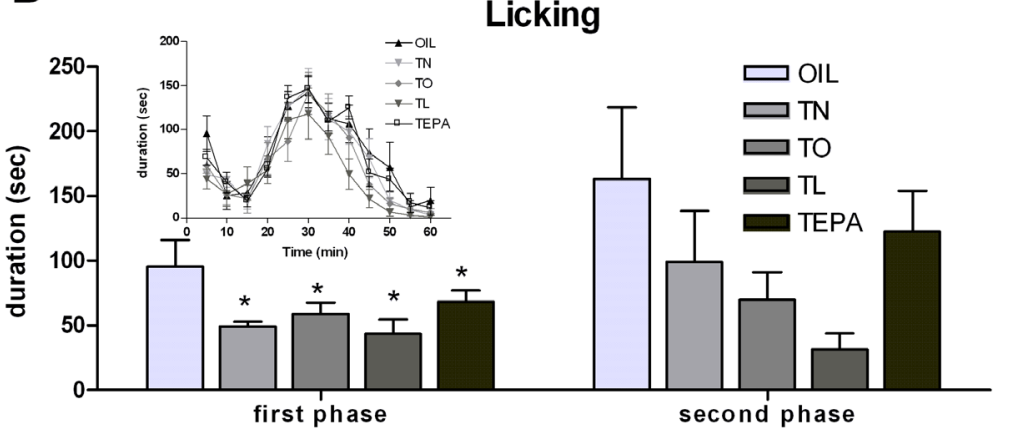

C

Flexing

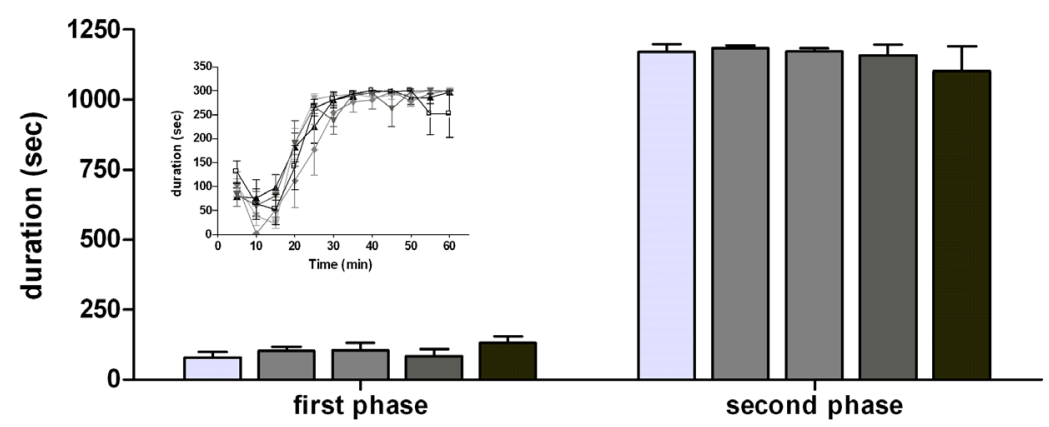

Figure 4. Formalin test (FT): histograms of total frequency or duration of each pain induced response during the first and the second phase of the FT in all the treated groups (OIL, TN, TO, TL, TEPA). Each insert represents the time course of the pain responses in the 60 min of the FT, divided into twelve 5-min periods. (A) Paw jerk frequency; (B) Licking duration; (C) Flexing duration. Data represent mean \pm SEM. ${ }^{*} \mathrm{p}<0.01$ vs OIL. 


\subsection{Hormone Plasma Levels}

The effects of treatments on testosterone and dihydrotestosterone plasma levels were examined at the end of the experiment. One-way ANOVA did not reveal any significant differences among groups (Figure 5).

\section{Discussion}

The main result of the present study is that ER RNA expression and protein levels are sensitive to treatment with testosterone esters, albeit differently in the two ER types. The T esters used in the present study were obtained [33] by combining the T molecule with unsaturated fatty acids presenting different degrees of unsaturation and belonging to the predominant fatty acid families: oleic, linoleic and eicosapentaenoic (EPA) acids. These compounds (T-oleic, T-linoleic and T-EPA) were found to be stable and not toxic in fibroblasts and astrocytes [33]. Thus it was possible to perform in vivo studies in intact male rats. In these subjects, spontaneous behaviors and testosterone and DHT plasma levels were not significantly affected by treatments, suggesting that all compounds were metabolized without apparent interference with the nervous and endocrine systems. However, important changes were observed in brain ER RNA expression and protein levels, suggesting possible long-term effects on cognitive functions.

Estrogens are known to modulate attention, learning and memory but also to have neuroprotective actions able to counteract inflammation or other brain injuries. Moreover, there is a strong suggestion that estrogen plays a key role in pain occurrence and modulation via both $\mathrm{ER} \alpha$ and $\mathrm{ER} \beta$ receptors. Since testosterone is the main source of estrogens in the brain (neurons and astrocytes have P450Arom to transform $\mathrm{T}$ into estradiol), understanding how circulating testosterone can regulate the expression of estrogen receptors is important. Indeed a change in the availability of $\operatorname{ER} \alpha$ and $\operatorname{ER} \beta$ proteins in sensory neurons could influence their sensitivity to estrogen. In the present study, we examined the levels of ER protein and mRNA in the hypothalamus, hippocampus and spinal cord using the regulation of both ER isoforms as a parameter for estrogen responsiveness (in this case to locally produced estrogens) and to investigate their modulation after hormonal manipulation.

Each treatment had a strong and independent affect on the transcription and expression of both estrogen receptors. While TN increased ER $\alpha$ in the hippocampus, TL not only blocked this increase but tended to decrease $\mathrm{ER} \alpha$ in this brain area. Interestingly $\mathrm{ER} \beta$ showed a completely different effect since the higher levels were in the TL group. In the hypothalamus, $\mathrm{ER} \alpha$ were decreased in the TO and TL groups, while $\mathrm{ER} \beta$ did not change. Similar changes were observed in the ER protein levels.

The use of entire tissue could mask T-induced changes in gene and protein expression that are neuron-specific, e.g. T might differentially regulate gene and protein expression depending on the neuron/cell type. Nevertheless, the results are highly consistent, indicating that the different FA attached to the T molecule could differently affect its interaction with cells. Interestingly, a high transcriptional level does not translate into an increased expression of protein, and vice versa. Although the protein expression patterns often match the mRNA expression patterns, there are examples in which ER protein levels are not correlated with ER mRNA expression [36] [37].

Estrogens exert their effects through genomic and non-genomic mechanisms [38] [39]; indeed their activation alters the expression of certain genes and neurotransmitters in sensory neurons [40] [41]. Recently it was shown that activation of astrocytes after injury or inflammation results in increased expression of ER and de novo ex-

A

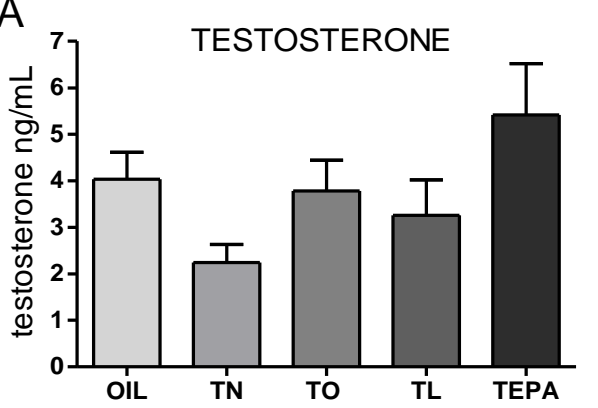

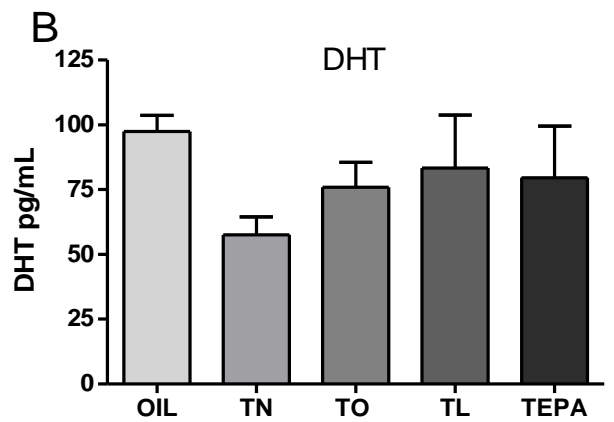

Figure 5. (A) Testosterone and (B) dihydrotestosterone (DHT) plasma levels determined in all treated groups (OIL TN, TP, TL AND TEPA) at the end of the formalin test. Each bar represents the mean \pm SEM. 
pression of aromatase [25]. In the spinal cord, ER $\alpha$ were found to mediate the pro-nociceptive effect of estradiol on visceral signal processing through activation of the MAPK pathway [42]. Furthermore, ER $\beta$ knockout mice showed lower nociceptive responses than wild type mice [43]. These findings are particularly interesting in the light of these preliminary results suggesting that substances modulating $\operatorname{ER} \alpha$ and $\operatorname{ER} \beta$ can positively modulate pain or inflammation in general.

It has been shown that ER expression is regulated by estrogens in the brain [44]-[46] as an auto-regulatory feedback loop [47]. Moreover, Patisaul et al. (1999) [48] demonstrated that ER $\alpha$ and ER $\beta$ mRNA expression is down-regulated by estrogen in a region-specific manner in the rat brain. The molecular mechanisms underlying the regulation of ER expression by testosterone have not been elucidated. However, since aromatase is the key enzyme for synthesis of estrogens from androgens and is responsible for controlling the androgen/estrogens ratio, it is possible that the down-regulation of ER protein present in some of our treatment groups might be due to increased local estrogen biosynthesis resulting from the circulating testosterone. In hippocampal neurons, aromatase-mediated estrogen production appears to be involved in an auto/paracrine feedback mechanism to regulate $\mathrm{ER} \alpha$ and $\mathrm{ER} \beta$ expression [49]. It is likely that estrogens induce proteasome-mediated proteolysis of ER $\alpha$ and ER $\beta$, a system responsible for degradation of most proteins in mammalian cells. This swift estrogen-dependent protein degradation could account for a rapid decline of ER protein by testosterone treatment without changes in the levels of ER mRNA. Alternatively, the testosterone may act post-transcriptionally to down-regulate ER $\alpha$ and ER $\beta$ protein levels. The mechanism for this is not currently known. Nonetheless, it is possible that testosterone activates proteolysis by inducing the expression of kinases that activate the ubiquitin proteasome pathway.

While the molecular actions of steroid hormones mediated by their receptors have been extensively studied in the brain and in peripheral tissues, considerably less is known about the molecular mechanisms that regulate the expression of the steroid hormone receptors themselves. However, the mechanisms underlying ER regulation by testosterone may involve different transcriptional and/or post-transcriptional events which will likely be cell and tissue specific as well as gender specific. Polyunsaturated fatty acids (PUFAs) are well known and widely utilized because of the variety of their biological effects, particularly those related to the cardiovascular system. Based on recent evidence we have hypothesized that the demonstrated analgesic action of testosterone [50] would be strengthened by supplementation of the testosterone with $(n-3)$ PUFAs, since $n-3$ FAs can modulate inflammatory metabolic pathways [51]. We used the formalin test because it allows quantification of pain intensity without any external interference. Once injected in the paw, the irritant induces pain responses that can be easily measured. Thus, this model can be used to evaluate modulation of the inflammatory condition by testosterone treatment. The formalin-induced responses revealed different analgesic effects of the treatments depending on the T-esters used: TO and TL were analgesic in terms of both paw jerk and licking, while no decrease in these responses was present in the TN group.

Therefore, these new esters involving important unsaturated FAs could play a role in the treatment of chronic pain, owing to not only their anti-inflammatory effect but also their ability to improve the stability and pharmacokinetics of testosterone. For this reason, the combination of an $n-3$ PUFA with testosterone could represent an interesting approach in hormone replacement therapy.

\section{Acknowledgements}

The present study was supported by the University of Siena, PRIN 2008 to AMA.

\section{References}

[1] Paul, S.M. and Purdy, R.H. (1992) Neuroactive Steroids. The FASEB Journal, 6, 2311-2322.

[2] Rupprecht, R. and Holsboer, F. (1999) Neuroactive Steroids: Mechanisms of Action and Neuropsychopharmacological Perspectives. Trends in Neurosciences, 22, 410-416. http://dx.doi.org/10.1016/S0166-2236(99)01399-5

[3] Rupprecht, R., di Michele, F., Hermann, B., Ströhle, A., Lancel, M., Romeo, E., et al. (2001) Neuroactive Steroids: Molecular Mechanisms of Action and Implications for Neuropsychopharmacology. Brain Research Reviews, 37, 59-67. http://dx.doi.org/10.1016/S0165-0173(01)00123-0

[4] Fillingim, R.B. and Ness, T.J. (2000) Sex-Related Hormonal Influences on Pain and Analgesic Responses. Neuroscience \& Biobehavioral Reviews, 24, 485-501. http://dx.doi.org/10.1016/S0149-7634(00)00017-8

[5] Negri-Cesi, P., Colciago, A., Celotti, F. and Motta, M. (2004) Sexual Differentiation of the Brain: Role of Testosterone and Its Active Metabolites. Journal of Endocrinological Investigation, 27, 120-127. 
[6] Smith, S.S. and Woolley, C.S. (2004) Cellular and Molecular Effects of Steroid Hormones on CNS Excitability. Cleveland Clinic Journal of Medicine, 71, S4-10. http://dx.doi.org/10.3949/ccjm.71.Suppl_2.S4

[7] Aloisi, A.M. and Bonifazi, M. (2006) Sex Hormones, Central Nervous System and Pain. Hormones and Behavior, 50, 1-7. http://dx.doi.org/10.1016/j.yhbeh.2005.12.002

[8] Vodo, S., Bechi, N., Petroni, A., Muscoli, C. and Aloisi, A.M. (2013) Testosterone-Induced Effects on Lipids and Inflammation. Mediators of Inflammation, 2013, Article ID: 183041.

[9] Mhyre, A.J. and Dorsa, D.M. (2006) Estrogen Activates Rapid Signaling in the Brain: Role of Estrogen Receptor Alpha and Estrogen Receptor Beta in Neurons and Glia. Neuroscience, 138, 851-858. http://dx.doi.org/10.1016/j.neuroscience.2005.10.019

[10] Pike, C.J., Nguyen, T.V., Ramsden, M., Yao, M., Murphy, M.P. and Rosario, E.R. (2008) Androgen Cell Signaling Pathways Involved in Neuroprotective Actions. Hormones and Behavior, 53, 693-705. http://dx.doi.org/10.1016/j.yhbeh.2007.11.006

[11] Craft, R.M., Mogil, J.S. and Aloisi, A.M. (2004) Sex Differences in Pain and Analgesia: The Role of Gonadal Hormones. European Journal of Pain, 8, 397-411. http://dx.doi.org/10.1016/j.ejpain.2004.01.003

[12] Fillingim, R.B., King, C.D., Ribeiro-Dasilva, M.C., Rahim-Williams, B. and Riley 3rd, J.L. (2009) Sex, Gender, and Pain: A Review of Recent Clinical and Experimental Findings. The Journal of Pain, 10, 447-485. http://dx.doi.org/10.1016/j.jpain.2008.12.001

[13] Kaergaard, A., Hansen, A.M., Rasmussen, K. and Andersen, J.H. (2000) Association between Plasma Testosterone and Work-Related Neck and Shoulder Disorders among Female Workers. Scandinavian Journal of Work, Environment \& Health, 26, 292-298. http://dx.doi.org/10.5271/sjweh.545

[14] Aloisi, A.M., Ceccarelli, I., Carlucci, M., Suman, A., Sindaco, G., Mameli, S., Paci, V., Ravaioli, L., Passavanti, G., Bachiocco, V. and Pari, G. (2011) Hormone Replacement Therapy in Morphine-Induced Hypogonadic Male Chronic Pain Patients. Reproductive Biology and Endocrinology, 9, 26. http://dx.doi.org/10.1186/1477-7827-9-26

[15] Ceccarelli, I., Scaramuzzino, A., Massafra, C. and Aloisi, A.M. (2003) The Behavioral and Neuronal Effects Induced by Repetitive Nociceptive Stimulation Are Affected by Gonadal Hormones in Male Rats. Pain, 104, 35-47. http://dx.doi.org/10.1016/S0304-3959(02)00460-8

[16] Gaumond, I., Arsenault, P. and Marchand, S. (2005) Specificity of Female and Male Sex Hormones on Excitatory and Inhibitory Phases of Formalin-Induced Nociceptive Responses. Brain Research, 1052, 105-111. http://dx.doi.org/10.1016/j.brainres.2005.06.011

[17] Vincent, K., Warnaby, C., Stagg, C.J., Moore, J., Kennedy, S. and Tracey, I. (2013) Brain Imaging Reveals that Engagement of Descending Inhibitory Pain Pathways in Healthy Women in a Low Endogenous Estradiol State Varies with Testosterone. Pain, 154, 515-524. http://dx.doi.org/10.1016/j.pain.2012.11.016

[18] Aloisi, A.M. (2003) Gonadal Hormones and Sex Differences in Pain Reactivity. Clinical Journal of Pain, 19, 168-174. http://dx.doi.org/10.1097/00002508-200305000-00004

[19] Ceccarelli, I., Casamenti, F., Massafra, C., Pepeu, G., Scali, C. and Aloisi, A.M. (1999) Effects of Novelty and Pain on Behavior and Hippocampal Extracellular ACh Levels in Male and Female Rats. Brain Research, 815, 169-176. http://dx.doi.org/10.1016/S0006-8993(98)01171-8

[20] Zimmerman, M.E., Pan, J.W., Hetherington, H.P., Lipton, M.L., Baigi, K. and Lipton, R.B. (2009) Hippocampal Correlates of Pain in Healthy Elderly Adults: A Pilot Study. Neurology, 73, 1567-1570. http://dx.doi.org/10.1212/WNL.0b013e3181c0d454

[21] Mutso, A.A., Radzicki, D., Baliki, M.N., Huang, L., Banisadr, G., Centeno, M.V., Radulovic, J., Martina, M., Miller, R.J. and Apkarian, A.V. (2012) Abnormalities in Hippocampal Functioning with Persistent Pain. Journal of Neuroscience, 32, 5747-5756. http://dx.doi.org/10.1523/JNEUROSCI.0587-12.2012

[22] Gondo, M., Moriguchi, Y., Kodama, N., Sato, N., Sudo, N., Kubo, C. and Komaki, G. (2012) Daily Physical Complaints and Hippocampal Function: An fMRI Study of Pain Modulation by Anxiety. NeuroImage, 63, 1011-1019. http://dx.doi.org/10.1016/j.neuroimage.2012.07.025

[23] Korol, D.L. (2004) Role of Estrogen in Balancing Contributions from Multiple Memory Systems. Neurobiology of Learning and Memory, 82, 309-323. http://dx.doi.org/10.1016/j.nlm.2004.07.006

[24] Hajszan, T. and MacLusky, N.J. (2006) Neurologic Links between Epilepsy and Depression in Women-Is Hippocampal Neuroplasticity the Key? Neurology, 66, S13-S22. http://dx.doi.org/10.1212/WNL.66.66_suppl_3.S13

[25] Acaz-Fonseca, E., Sanchez-Gonzalez, R., Azcoitia, I., Arevalo, M.A. and Garcia-Segura, L.M. (2014) Role of Astrocytes in the Neuroprotective Actions of $17 \beta$-Estradiol and Selective Estrogen Receptor Modulators. Molecular and Cellular Endocrinology, 389, 48-57.

[26] De Maddalena, C., Bellini, M., Berra, M., Meriggiola, M.C. and Aloisi, A.M. (2012) Opioid-Induced Hypogonadism: Why and How to Treat It. Pain Physician, 15, ES111-ES118. 
[27] Tajar, A., McBeth, J., Lee, D.M., Macfarlane, G.J., Huhtaniemi, I.T., Finn, J.D., Bartfai, G., Boonen, S., Casanueva, F.F., Forti, G., Giwercman, A., Han, T.S., Kula, K., Labrie, F., Lean, M.E., Pendleton, N., Punab, M., Silman, A.J., Vanderschueren, D., O’Neill, T.W. and Wu, F.C. (2011) Elevated Levels of Gonadotrophins but Not Sex Steroids Are Associated with Musculoskeletal Pain in Middle-Aged and Older European Men. Pain, 152, 1495-1501. http://dx.doi.org/10.1016/j.pain.2011.01.048

[28] Saad, F., Aversa, A., Isidori, A.M. and Gooren, L.J. (2012) Testosterone as Potential Effective Therapy in Treatment of Obesity in Men with Testosterone Deficiency: A Review. Current Diabetes Reviews, 8, 131-143. http://dx.doi.org/10.2174/157339912799424573

[29] Siri-Tarino, P.W., Sun, Q., Hu, F.B. and Krauss, R.M. (2010) Saturated Fat, Carbohydrate, and Cardiovascular Disease. American Journal of Clinical Nutrition, 91, 502-509. http://dx.doi.org/10.3945/ajcn.2008.26285

[30] Petroni, A. (2007) Medicament Based on a Monoester of Steroids with Long Chain Fatty Acids. Pub. No. WO/2007/ 068434.

[31] Phillips, G., Pinkernell, B. and Jing, T. (1994) The Association of Hypotestosteronemia with Coronary Artery Disease in Men. Arteriosclerosis, Thrombosis, and Vascular Biology, 14, 701-706. http://dx.doi.org/10.1161/01.ATV.14.5.701

[32] Ceccarelli, I., Rossi, A., Maddalena, M., Weber, E. and Aloisi, A.M. (2009) Effects of Morphine on Testosterone Levels in Rat C6 Glioma Cells: Modulation by Anastrozole. Journal of Cellular Physiology, 221, 1-4. http://dx.doi.org/10.1002/jcp.21830

[33] Aiello, F., Garofalo, A., Aloisi, A.M., Lamponi, S., Magnani, A. and Petroni, A. (2013) Synthesis of Esters of Androgens with Unsaturated Fatty Acids for Androgen Requiring Therapy. Journal of Endocrinological Investigation, 36, 390-395.

[34] Zimmermann, M. (1983) Ethical Guidelines for Investigations of Experimental Pain in Conscious Animals. Pain, 16, 109-110. http://dx.doi.org/10.1016/0304-3959(83)90201-4

[35] Dominguez, R. and Mitchevych, P. (2010) Estradiol Rapidly Regulates Membrane Estrogen Receptor $\alpha$ Levels in Hypothalamic Neurons. Journal of Neuroscience, 30, 12589-12596. http://dx.doi.org/10.1523/JNEUROSCI.1038-10.2010

[36] Shughrue, P.J. and Merchenthalerm, I. (2001) Distribution of Estrogen Receptor $\beta$ Immunoreactivity in the Rat Central Nervous System. Journal of Comparative Neurology, 436, 64-81. http://dx.doi.org/10.1002/cne.1054

[37] Perez, C., Falero, A., Llanes, N., Hung, B.R., Herve, M.E., Palmero, A. and Martii, E. (2003) Resistance to Androstanes as an Approach for Androstandienedione Yield Enhancement in Industrial Mycobacteria. Journal of Industrial Microbiology and Biotechnology, 30, 623-626. http://dx.doi.org/10.1007/s10295-003-0079-4

[38] Toran-Allerand, C.D., Singh, M. and Setalo Jr., G. (1999) Novel Mechanisms of Estrogen Action in the Brain: New Players in an Old Story. Frontiers in Neuroendocrinology, 20, 97-121. http://dx.doi.org/10.1006/frne.1999.0177

[39] Purves-Tyson, T.D. and Keast, J.R. (2004) Rapid Actions of Estradiol on Cyclic Amp Response-Element Binding Protein Phosphorylation in Dorsal Root Ganglion Neurons. Neuroscience, 129, 629-637. http://dx.doi.org/10.1016/j.neuroscience.2004.08.019

[40] Sohrabji, F., Miranda, R.C. and Toran-Allerand, C.D. (1994) Estrogen Differentially Regulates Estrogen and Nerve Growth Factor Receptor mRNAs in Adult Sensory Neurons. Journal of Neuroscience, 14, 459-471.

[41] Allen, A.L. and McCarson, K.E. (2005) Estrogen Increases Nociception-Evoked Brain-Derived Neurotrophic Factor Gene Expression in the Female Rat. Neuroendocrinology, 81, 193-199. http://dx.doi.org/10.1159/000087002

[42] Ji, Y., Tang, B. and Traub, R.J. (2011) Spinal Estrogen Receptor Alpha Mediates Estradiol-Induced Pronociception in a Visceral Pain Model in the Rat. Pain, 152, 1182-1191. http://dx.doi.org/10.1016/j.pain.2011.01.046

[43] Spooner, M.F., Robichaud, P., Carrier, J.C. and Marchand, S. (2007) Endogenous Pain Modulation during the Formalin Test in Estrogen Receptor Beta Knockout Mice. Neuroscience, 150, 675-680. http://dx.doi.org/10.1016/j.neuroscience.2007.09.037

[44] Österlund, M.K., Gustafsson, J.A., Keller, E. and Hurd, Y.L. (2000) Estrogen Receptor $\beta$ (ER $\beta$ ) Messenger Ribonucleic Acid (mRNA) Expression within the Human Forebrain: Distinct Distribution Pattern to ER $\alpha$ mRNA. Journal of Clinical Endocrinology \& Metabolism, 85, 3840-3846.

[45] Schreihofer, D.A., Stoler, M.H. and Shupnik, M.A. (2000) Differential Expression and Regulation of Estrogen Receptors (ERs) in Rat Pituitary and Cell Lines: Estrogen Decreases ER $\alpha$ Protein and Estrogen Responsiveness. Endocrinology, 141, 2174-2184.

[46] Tena-Sempere, M., Gonzalez, L.C., Pinilla, L., Huhtaniemi, I. and Aguilar, E. (2001) Neonatal Imprinting and Regulation of Estrogen Receptor Alpha and Beta mRNA Expression by Estrogen in the Pituitary and Hypothalamus of the Male Rat. Neuroendocrinology, 73, 12-25. http://dx.doi.org/10.1159/000054616

[47] Alarid, E.T., Bakopoulos, N. and Solodin, N. (1999) Proteasome-Mediated Proteolysis of Estrogen Receptor: A Novel Component in Autologous Down-Regulation. Molecular Endocrinology, 13, 1522-1534. http://dx.doi.org/10.1210/mend.13.9.0337 
[48] Patisaul, H.B., Whitten, P.L. and Young, L.J. (1999) Regulation of Estrogen Receptor Beta mRNA in the Brain: Opposite Effects of $17 \beta$-Estradiol and the Phytoestrogen, Coumestrol. Molecular Brain Research, 67, 165-171. http://dx.doi.org/10.1016/S0169-328X(99)00058-3

[49] Prange-Kiel, J., Wehrenberg, U., Jarry, H. and Rune, G.M. (2003) Para/Autocrine Regulation of Estrogen Receptors in Hippocampal Neurons. Hippocampus, 13, 226-234. http://dx.doi.org/10.1002/hipo.10075

[50] Aloisi, A.M., Ceccarelli, I., Fiorenzani, P., De Padova, A.M. and Massafra, C. (2004) Testosterone Affects FormalinInduced Responses Differently in Male and Female Rats. Neuroscience Letters, 361, 262-264. http://dx.doi.org/10.1016/j.neulet.2003.12.023

[51] Rossmeisl, M., Medrikova, D., van Schothorst, E.M., Pavlisova, J., Kuda, O., Hensler, M., Bardova, K., Flachs, P., Stankova, B., Vecka, M., Tvrzicka, E., Zak, A., Keijer, J. and Kopecky, J. (2013) Omega-3 Phospholipids from Fish Suppress Hepatic Steatosis by Integrated Inhibition of Biosynthetic Pathways in Dietary Obese Mice. Biochimica et Biophysica Acta, 1841, 267-278. http://dx.doi.org/10.1016/j.bbalip.2013.11.010 